\title{
Correction to: FDG uptake in cervical lymph nodes in children without head and neck cancer
}

\author{
Reza Vali $^{1}$ - Alaa Bakkari ${ }^{1} \cdot$ Eman Marie $^{1} \cdot$ Mahnaz Kousha $^{1} \cdot$ Martin Charron $^{2} \cdot$ Amer Shammas $^{1}$
}

Published online: 13 December 2017

(C) Springer-Verlag GmbH Germany, part of Springer Nature 2017

Correction to: Pediatr Radiol (2017) 47:860-867

https://doi.org/10.1007/s00247-017-3835-8

The original version of this article unfortunately contained a mistake. Author name Alaa Bakkari was incorrect. The correct spelling is given above.

The online version of the original article can be found at https://doi.org/ 10.1007/s00247-017-3835-8.

$\checkmark$ Reza Vali

reza.vali@sickkids.ca

1 Department of Diagnostic Imaging,

The Hospital for Sick Children, University of Toronto,

555 University Ave, Toronto, ON M5G 1X8, Canada

2 Brampton Nuclear Services, Toronto, ON, Canada 